\title{
Clinical efficacy and safety results for dose escalation of somatostatin receptor ligands in patients with acromegaly: a literature review
}

\author{
Maria Fleseriu
}

Published online: 15 December 2010

(C) The Author(s) 2010. This article is published with open access at Springerlink.com

\begin{abstract}
Acromegaly is a rare disease with a multifaceted clinical presentation. In $90-95 \%$ of patients with acromegaly, the disease is caused by a growth hormone (GH)-secreting pituitary adenoma with elevated GH levels that ultimately induce excessive hepatic secretion of insulin-like growth factor-1 (IGF-1). Somatostatin receptor ligands (SRLs) are considered the standard medical choice for the treatment of acromegaly, and normalization of GH and IGF-1 is attainable with effective therapy. This review aims to summarize the literature relative to SRL dose escalation therapy in patients with acromegaly. A United States National Library of Medicine PubMed search of SRL's was conducted using the following search terms: ((((LAR) OR ATG) OR octreotide) OR lanreotide Autogel) AND acromegaly. Related articles in non peer-reviewed journals were excluded. The rationale and benefits of SRL dose optimization therapy were investigated with emphasis on describing the clinical recognition, treatment, and management of patients with acromegaly. We found that dose escalation could provide additional biochemical control of acromegaly in patients who are inadequately controlled with conventional starting doses of octreotide LAR and lanreotide Autogel ${ }^{\circledR}$. Furthermore, patients should routinely have their GH and IGF-1 levels closely monitored and their SRL dose increased or decreased thereafter according to individual response.
\end{abstract}

M. Fleseriu ( $\square$ )

Departments of Neurological Surgery and Medicine, Northwest Pituitary Center, Oregon Health \& Science University, 3181 SW Sam Jackson Park Road, (BTE 472), Portland, OR 97239, USA e-mail: fleseriu@ohsu.edu
Keywords Octreotide LAR $\cdot$ Lanreotide Autogel ${ }^{\circledR}$. Dose optimization · Acromegaly

\section{Introduction}

Acromegaly is a rare disease with a multifaceted clinical presentation. The estimated prevalence of acromegaly worldwide is considered to be around 60 cases per million with approximately three new cases per million annually $[1,2]$. However, more recent European data pertinent to the prevalence of clinically significant pituitary adenomas suggests that acromegaly could be more common [3]. In most patients with acromegaly the disease is caused by a growth hormone $(\mathrm{GH})$-secreting pituitary adenoma with elevated GH levels that ultimately induce excessive hepatic secretion of insulin-like growth factor-1 (IGF-1) [4]. The pathologic effects of GH excess are acral overgrowth (i.e., macrognathia, enlargement of the facial bone structure, and enlarged hands and feet); visceral overgrowth, including macroglossia; and enlarged thyroid, liver, kidney, and heart. Compared with healthy subjects, patients with untreated acromegaly experience increased morbidity and mortality [5], which is primarily due to cardiovascular disease [6]. Despite long-term cure of GH excess, patients are also likely to experience a decrease in quality of life [7]. Control of GH/IGF-1 hypersecretion has been shown to reduce mortality rates to levels similar to those in patients without acromegaly $[6,8]$. Somatostatin receptor ligands (SRLs) are considered the medical treatment of choice for acromegaly and normalization of GH and IGF-1 is attainable with effective therapy. However, some patients do not achieve biochemical control with a standard dose of a SRL. Recent treatment guidelines and clinical studies suggest that SRL dose titration can improve control of $\mathrm{GH}$ and 
IGF-1 in patients that have not achieved a full response to an initial SRL dose [9, 10]. In this review we summarize the literature relative to SRL dose escalation therapy in patients with acromegaly. We also discuss clinical evidence in support of optimal medical therapy that requires individual SRL tailoring, including high-dose treatments in acromegaly patients.

\section{Literature search}

A United States National Library of Medicine PubMed search was conducted for the following: ((((LAR) OR ATG) OR octreotide) OR lanreotide Autogel) AND acromegaly, through September 2010. Related articles in non peer-reviewed journals were excluded. The studies selected for review included those that evaluated the initial patient response to SRL treatment followed by an attempt to improve patient response with dose optimization therapy, including either higher dose or higher frequency of doses.

\section{Overall treatment goals}

Treatment of acromegaly is complex and most cases require a stepwise, multimodality approach to control disease progression. The treatment goals for patients with acromegaly include: inhibiting $\mathrm{GH}$ hypersecretion, normalizing IGF-1 levels, reducing tumor mass, and alleviating the comorbidities [4, 9, 11]. Adverse outcomes have been linked to increases in both GH and IGF-1 levels, therefore stringent biochemical criteria have been applied over time (Fig. 1) [12]. Complete biochemical control is defined as serum GH levels of $<1 \mu \mathrm{g} / \mathrm{l}$ if tested using a sensitive immunoassay or $\leq 2.5 \mu \mathrm{g} / \mathrm{l}$ if measured by radioimmunoassay, $\mathrm{GH}$ levels of $<0.4 \mu \mathrm{g} / \mathrm{l}$ after oral glucose tolerance test (OGTT), and normalization of serum IGF-1 levels compared to age- and sex-matched controls $[9,10,12]$. The algorithm depicted in Fig. 2 represents the current surgical and pharmacological options for the diagnosis and treatment of acromegaly [9, 10]. Surgery is effective as a first-line treatment option for biochemical control in approximately $80 \%$ of patients with microadenoma [13-16]. Surgical treatment has the dual advantage of rapidly improving symptoms caused by mass effect of the tumor and significantly reducing or normalizing GH/IGF-1 concentrations. Cure rates with larger and invasive tumors are much smaller (50-60\%) and the initiation of medical therapy is recommended after surgery.

\section{Somatostatin receptor ligands}

In the last two decades, the development of highly specific and selective synthetic somatostatin analogs that act as ligands for the somatostatin receptor has led to significant progress in the treatment of acromegaly [17]. The leading consensus guidelines for the treatment of acromegaly maintain that SRLs, have emerged as the primary medical therapy for controlling GH excess [18]. In addition, recent results show that octreotide LAR can be a viable option for the first-line treatment of acromegaly as long-term treatment with octreotide LAR does not significantly differ from surgery [19].

SRLs act at four levels to target abnormal GH secretion: (1) suppression of $\mathrm{GH}$ secretion from the pituitary and from GH-secreting adenomas, (2) decrease in binding to hepatocyte $\mathrm{GH}$ receptors, (3) inhibition of hepatic IGF-1 synthesis, and (4) control of tumor growth [20]. Two commercially available SRLs; octreotide LAR and lanreotide Autogel (ATG), have unique therapeutic effects based on their different pharmacokinetic properties and

Fig. 1 Interpretation of $\mathrm{GH}$ and IGF-1 levels in acromegaly. (C) 2010, The Endocrine Society, reproduced with permission. Giustina et al. [12]. GHRA growth hormone receptor antagonist, $O G T T$ oral glucose tolerance test, $D R$ discretionary recommendation, $S R$ strong recommendation

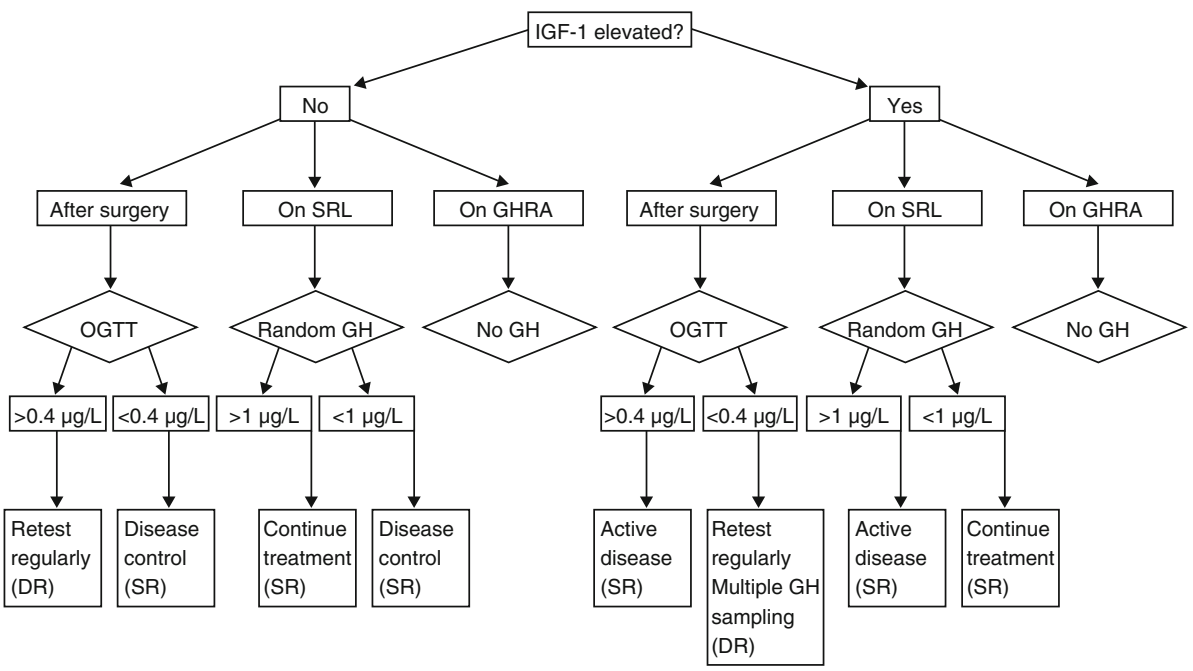


Fig. 2 The management strategy for the treatment of acromegaly. Disease control is defined as attaining the $\mathrm{GH}$ and IGF-1 levels outlined in the text. First level, surgery or medical therapy $(S R L)$; second level, $S R L$ therapy, dose adjustment, and monitor disease progression; third level, MRI; fourth level, radiation or pegvisomant therapy; fifth level, monitor disease progression or return patient to surgery. (C) 2009, The Endocrine Society, reproduced with permission. Melmed et al. [10]

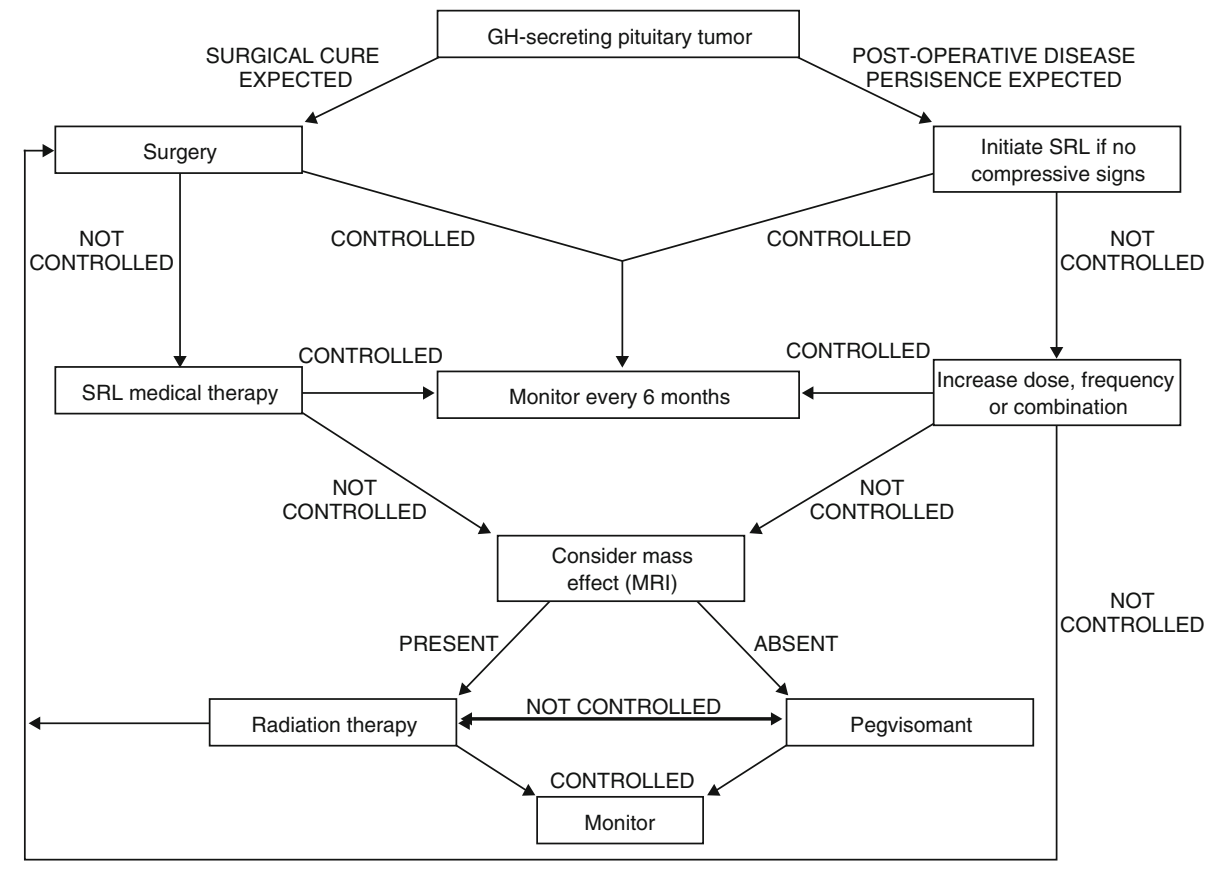

patterns of receptor affinity. They each bind with varying affinity to the five somatostatin receptors (SSTRs) but both bind preferentially to SSTR2 [21]. Resistance to SRL therapy that is reported in some patients could be explained, in part, by variable tumor expression and/or decreased density of SSTR2 expression [22]. Currently, there are other SRLs in clinical trials: the next generation SRL, pasireotide (SOM230) is in phase 3 development and a chimeric molecule, dopamine-SRL (dopastatin), is in phase 2 development. Pasireotide is a novel multi-ligand SRL with a unique structure, potent in vitro and in vivo inhibitory effects on GH and IGF-1 release, and a high binding affinity to SSTR1, $-2,-3$, and -5 with up to a 40fold greater affinity for SSTR5 than octreotide. Based on phase 2 results in patients with acromegaly [23], pasireotide is considered a promising therapeutic candidate with several potential advantages over currently used SRLs in GH-secreting adenomas that are either unresponsive or resistant to current therapy [24].

The use of octreotide LAR for the treatment of patients with acromegaly is supported by more than 20 years of clinical research and experience [18]. The usual starting dose for octreotide LAR is $20 \mathrm{mg}$ with titration down to $10 \mathrm{mg}$ or up to $30,40 \mathrm{or} 60 \mathrm{mg}$, based on the need to attain biochemical control [25]. An initial study that evaluated the efficacy, tolerability, and pharmacokinetics of octreotide LAR determined that a $10 \mathrm{mg}$ dose was considerably less effective than a 20 or $30 \mathrm{mg}$ dose, and that an interval of 60 days between injections seemed too long. Much better control was achieved by delivering either a 20 or $30 \mathrm{mg}$ dose every 28 or 42 days [26, 27].
A more recent development has been the introduction of lanreotide ATG, a supersaturated aqueous formulation in a prefilled syringe that requires deep subcutaneous administration every 28 days [28]. The usual starting dose of lanreotide ATG is $90 \mathrm{mg}$ every 4 weeks with further titration up to $120 \mathrm{mg}$ or down to $60 \mathrm{mg}$ after 3 months based on the degree of biochemical response [29]. Longer intervals between injections have also been suggested $[29,30]$.

A large variability in the clinical response to SRL therapy is reported in the published literature. Clinical results of treatment with conventional doses of octreotide LAR (20-30 mg/month) show that complete biochemical control (GH levels $\leq 2.5 \mu \mathrm{g} / \mathrm{l}$ and IGF-1 normalization) is achieved in between 38 and $85 \%$ and $33-75 \%$ of patients, respectively [31-37]. Lanreotide slow release (SR) at conventional doses reduced plasma GH levels $(<5 \mu \mathrm{g} / \mathrm{l})$ in $54-68 \%$ of patients and normalized IGF-1 levels in $35-63 \%$ of patients $[38,39]$.

Additionally, the selection of patients who are expected to benefit from treatment with SRLs [31] and the optimal time to evaluate their response has changed over time. Consequently, Cozzi et al. suggested that clinicians evaluate patients 3-6 months after starting octreotide LAR therapy rather than discontinuing treatment at 3 months since the change in GH and IGF-1 levels after 6 months of treatment can predict the patients' response to treatment [34]. Elevated baseline GH and IGF-1 levels were not found to be accurate predictors of patient response to SRL therapy and thus SRL treatment should be also considered in such patients [34]. Most importantly, 
there is an ever-increasing quantity of clinical evidence that supports dose optimization with SRLs [40-42]. Recently updated guidelines state that patients should be continually monitored and, if necessary, recommend that dose optimization of SRL therapy should be performed at 3-month intervals based on the patient response [10, 43]. Collectively, these reports demonstrate that dose escalation, including high-dose treatment, improves the symptoms and comorbidities in patients with acromegaly without significant change to the safety and adverse events observed with conventional doses.

In patients with different treatment histories (mixed populations), the efficacy of octreotide LAR appears to be generally similar to that of lanreotide ATG and slightly better than that of lanreotide SR, according to data from switching or crossover studies [44, 45]. Patients who had previously responded to treatment with subcutaneous octreotide showed the greatest response. A number of studies have been carried out to compare the biochemical efficacy of octreotide LAR and lanreotide SR. However, these studies are almost exclusively openlabel, prospective studies with varying inclusion criteria. A meta-analysis of the results from 44 available trials that compared the efficacy of octreotide LAR and lanreotide SR determined that the biochemical efficacy of octreotide LAR is greater than that of lanreotide SR among subjects not selected for prior SRL responsiveness [46]. Other reviews of SRL therapy suggest that lanreotide ATG and octreotide LAR are of equivalent efficacy; however, a robust analysis is not possible given the limited power of the studies reviewed [44, 45]. The efficacy of SRLs should continue to be evaluated in prospective, randomized trials evaluating efficacy with respect to $\mathrm{GH}$ control and tumor shrinkage.

\section{Rationale and benefits of SRL dose optimization therapy}

In patients with insufficient biochemical response to a specific SRL dose, both dose optimization and/or addition of another therapy have been suggested [36, 44]. Treatment guidelines recommend evaluation of biochemical control and dose titration of the SRL every 3 months if appropriate [43]. Combination therapy has inherent advantages, but it is outside the focus of the present review.

Control of GH and IGF-1 diminishes and reduces mortality to expected levels $[8,47,48]$. In select cases such as large residual tumors with cavernous sinus invasion, elevated baseline GH and IGF-1, multiple co-morbidities, and longer duration of the disease, our approach is to start treatment with octreotide LAR $30 \mathrm{mg}$ or lanreotide ATG $120 \mathrm{mg}$ every 28 days for 3 months. Subsequent dose titration, either up or down, is based on the biochemical results and the patient's clinical response. If the patient's response is inadequate, the octreotide LAR dose is increased to $40 \mathrm{mg} / \mathrm{month}$. This treatment approach is similar to other established endocrinology centers [40]. Presently, our experience at the Northwest Pituitary Center at Oregon Health \& Science University with high-dose SRL treatment is limited to octreotide LAR. If the patient does not respond to the higher dose we proceed to combination therapy without discontinuation of SRLs, albeit at lower doses.

A selection of recent clinical reports describing the benefit of dose-optimization therapy with octreotide LAR and lanreotide ATG are summarized in Tables 1 and 2, respectively. In one of the earliest studies, Lancranjan et al. demonstrated that dose escalation with octreotide LAR from 20 to $30 \mathrm{mg} / \mathrm{month}$ in 22 patients reduced the mean GH level by $26 \%$ at 48 weeks [36]. In a 2-year study of 36

Table 1 Benefits of octreotide LAR dose optimization therapy

\begin{tabular}{|c|c|c|c|c|c|c|}
\hline Reference & $\begin{array}{l}\text { Highest dose } \\
\text { (mg/month) }\end{array}$ & $\begin{array}{l}\text { Patients on this } \\
\text { dose }(\%)\end{array}$ & $\begin{array}{l}\text { Total number } \\
\text { of patients (n) }\end{array}$ & $\begin{array}{l}\text { Duration of } \\
\text { treatment }\end{array}$ & $\begin{array}{l}\text { Patients with GH } \\
\leq 2.5 \mu \mathrm{g} / 1(\%)\end{array}$ & $\begin{array}{l}\text { Patients with } \\
\text { normalized IGF-1 (\%) }\end{array}$ \\
\hline Lancranjan et al. [36] & 30 & 15 & 151 & 12 months & 69.8 & 65.8 \\
\hline \multirow[t]{2}{*}{ Colao et al. [32] } & 30 & 33 & 36 & 12-24 months & 69.4 & 61.1 \\
\hline & 40 & 19 & & & & \\
\hline \multirow[t]{2}{*}{ Cozzi et al. [34] } & 30 & 38 & 110 & 4 years & 72 & 75 \\
\hline & 40 & 4 & & & & \\
\hline \multirow[t]{2}{*}{ Colao et al. [51] } & 30 & 27 & 56 & 24 months & 86 & 84 \\
\hline & 40 & 30 & & & & \\
\hline Colao et al. [19] & 30 & $\begin{array}{r}82 \text { (of safety } \\
\text { population) }\end{array}$ & $\begin{array}{l}40 \text { (protocol } \\
\text { completers) }\end{array}$ & 50 weeks & $\begin{array}{l}27.5 \text { (Patients achi } \\
\text { control) }\end{array}$ & g both GH and IGF-1 \\
\hline \multirow[t]{2}{*}{ Giustina et al. [56] } & 60 & 11 & 26 & 24 weeks & $27 *$ & 36 \\
\hline & 30 (every 3 weeks) & 15 & & & 0 & 0 \\
\hline
\end{tabular}

$* \mathrm{GH}<2 \mu \mathrm{g} / 1$ 
Table 2 Benefits of lanreotide ATG dose optimization therapy

\begin{tabular}{|c|c|c|c|c|c|c|}
\hline Reference & $\begin{array}{l}\text { Highest dose } \\
\text { (mg/month) }\end{array}$ & $\begin{array}{l}\text { Patients on this } \\
\text { dose }(\%)\end{array}$ & $\begin{array}{l}\text { Total number } \\
\text { of patients (n) }\end{array}$ & $\begin{array}{l}\text { Duration of } \\
\text { treatment }\end{array}$ & $\begin{array}{l}\text { Patients with GH } \\
\leq 2.5 \mu \mathrm{g} / 1(\%)\end{array}$ & $\begin{array}{l}\text { Patients with } \\
\text { normalized IGF-1 (\%) }\end{array}$ \\
\hline Caron et al. [29] & $120 \mathrm{mg}$ & 48 & 130 & 1 year & 68 & 50 \\
\hline \multirow[t]{3}{*}{ Ronchi et al. [30] } & $120 \mathrm{mg} / 8$ week & 27 & 6 & 42 weeks & 62 & 43 \\
\hline & $120 \mathrm{mg} / 6$ week & 18 & 4 & 36 weeks & & \\
\hline & $120 \mathrm{mg} / 4$ week & 55 & 12 & 34 weeks & & \\
\hline Attanasio et al. [58] & $180 \mathrm{mg}$ & 4 & 26 & 1 year & 42 & 54 \\
\hline Chanson et al. [49] & $120 \mathrm{mg}$ & 73 & 63 & 48 weeks & 85 & 43 \\
\hline Melmed et al. [65] & $120 \mathrm{mg}$ & 65 & 99 & 52 weeks & 38 & 54 \\
\hline
\end{tabular}

patients with acromegaly by Colao et al., $43 \%$ of patients achieved control of both GH and IGF-1 levels when the starting dose of octreotide LAR (20 mg/month) was increased to $30 \mathrm{mg} / \mathrm{month}$ and an additional $20 \%$ achieved biochemical control upon an increase to $40 \mathrm{mg} / \mathrm{month}$ [32]. Another trial conducted on 110 patients treated for up to 54 months with octreotide LAR reported that dose optimization may provide a significant benefit for patients with acromegaly [34]. Dose titration was based on IGF-1 normalization and increasing the starting dose of octreotide LAR from 20 to $30 \mathrm{mg} / \mathrm{month}$ significantly decreased IGF-1. At the end of the study $38 \%$ of patients $(n=42)$ were being treated with octreotide LAR $30 \mathrm{mg} / \mathrm{month}$, $4 \%$ were treated with $40 \mathrm{mg} / \mathrm{month}$ while $33 \%$ continued on the starting dose (20 mg/month).

The efficacy of titrated versus fixed doses of lanreotide ATG has been compared and the same improvement in patient outcome with dose optimization was reported. After 1 year of treatment, the mean plasma GH and IGF-1 concentrations in 130 patients were significantly lower for titrated lanreotide ATG than with fixed doses of lanreotide ATG (Fig. 3) [29]. The efficacy of lanreotide ATG in decreasing $\mathrm{GH}$ and IGF-1 has also been confirmed in patients previously treated with octreotide LAR. After a washout period, patients were switched to lanreotide ATG (120 mg) and the time between doses was adjusted based on the GH and IGF-1 response. Based on the need for additional treatment, the frequency was increased in 12/23 patients to every 4 weeks, $4 / 23$ patients remained on the original starting dose every 6 weeks, and $6 / 23$ patients were reduced to treatment every 8 weeks. At the end of the study, the number of patients that achieved $\mathrm{GH}<2.5 \mu \mathrm{g} / 1$ and normalized IGF-1 was 62 and $43 \%$ patients, respectively [30]. In another study, 63 patients with acromegaly were treated with lanreotide ATG (90 mg/4 weeks) with the dose adjusted to achieve normalized, age- and sexmatched, levels of IGF-1. By the end of the study $73 \%$ of patients required an increase to $120 \mathrm{mg}$ [49]. A randomized placebo-controlled study in an unselected population of 99

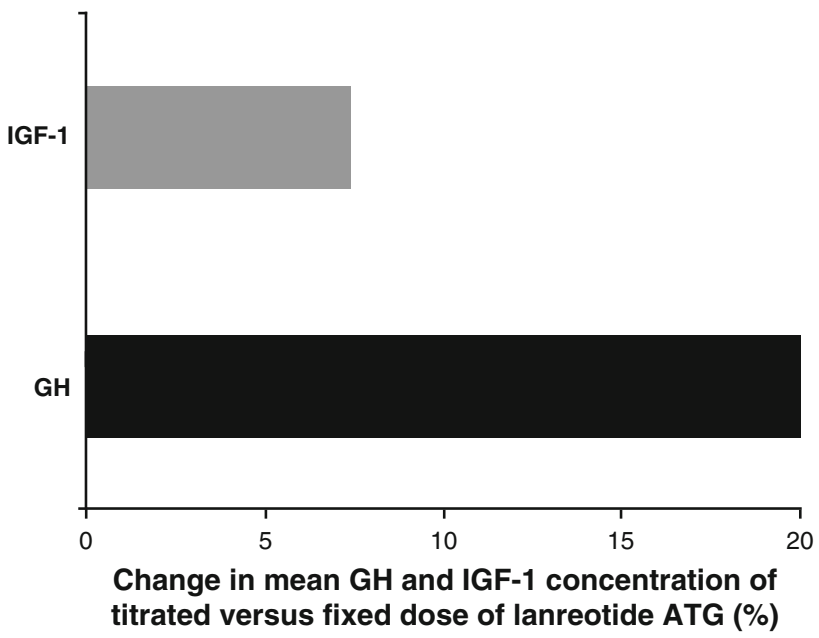

Fig. 3 Percent reduction of GH and IGF-1 concentrations at 12 months in patients with acromegaly treated with titrated versus fixed doses of lanreotide ATG

patients published in 2010 showed that lanreotide ATG was effective in controlling both $\mathrm{GH}$ and IGF-1 hypersecretion: $54 \%$ of patients had normalized IGF-1 and $38 \%$ achieved a combined criterion of $\mathrm{GH}$ level $\leq 2.5 \mu \mathrm{g} / 1$ and normalized IGF-1. Unsurprisingly, at the end of the open-label phase, $65 / 99$ patients were on the highest dose (120 mg every 4 weeks) [50].

\section{Use of SRLs as primary therapy}

Of late, much interest has surrounded the use of SRLs in primary therapy or preoperative treatment to improve surgical outcomes, and dose optimization therapy has also proven beneficial in first-line treatment of patients with acromegaly. A 2-year dose-escalation study by Colao et al. using octreotide LAR as the first-line therapy in 56 patients with acromegaly demonstrated that $32 / 56(57 \%)$ required a 
dose increase from the starting dose of $20 \mathrm{mg} / \mathrm{month}$ (group A) to either $30 \mathrm{mg} / \mathrm{month}$ (group B) or $40 \mathrm{mg}$ / month (group $\mathrm{C}$ ) to achieve control of GH and IGF-1 levels. At 24 months, control of GH and IGF-1 was achieved in $24 / 56(42.9 \%)$ patients treated with octreotide LAR $20 \mathrm{mg} / \mathrm{month}, 15 / 56(26.8 \%)$ patients receiving $30 \mathrm{mg} / \mathrm{month}$ and 6/56 (10.7\%) patients who had their octreotide LAR dose increased to $40 \mathrm{mg} / \mathrm{month}$ (Fig. 4) [51]. Overall, dose optimization clearly benefited the patients in this study such that $86 \%$ of patients achieved GH levels of $\leq 2.5 \mu \mathrm{g} / \mathrm{l}$ and $84 \%$ achieved normalized IGF-1 levels. More importantly, a third of the patients that were not controlled on a lower dose achieved remission after increasing their dose. A different approach was tried in another 12-month, open-label, prospective study [52]. Twenty-six newly diagnosed patients with acromegaly were treated with lanreotide ATG (120 mg/4 weeks). The interval between injections was increased to every 6-8 weeks in patients that achieved biochemical control (GH $\leq 2.5 \mu \mathrm{g} / 1$ and normalized IGF-1). After 12 months, biochemical control was achieved in 14/26 (54\%) patients with nine patients still receiving the lanreotide dose every 4 weeks, while the dosage was delayed to every 6 weeks in eight patients and every 8 weeks in nine patients. This dosing regimen also induced at least $25 \%$ tumor shrinkage in $77 \%$ of the patients in the study.

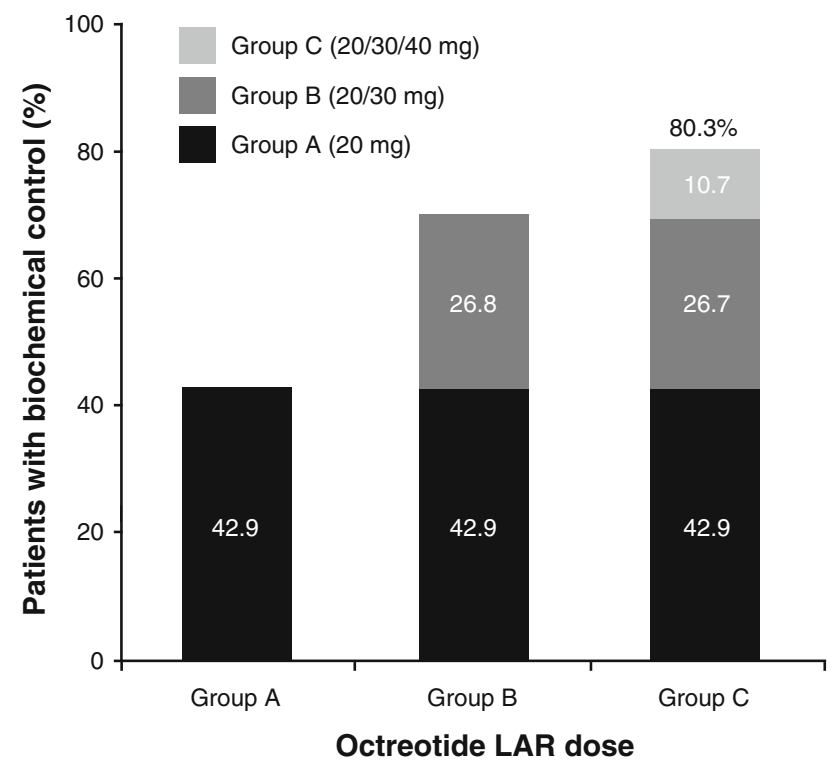

Fig. 4 Increase in the proportion of octreotide LAR patients with control of GH and IGF-1 after dose optimization therapy. Group A represents patients that were started and remained on the $20 \mathrm{mg} /$ month dose. Group B represents patients whose starting dose was increased to $30 \mathrm{mg} / \mathrm{month}$. Group $C$ represents patients whose dose was increased further to $40 \mathrm{mg} / \mathrm{month}$

\section{Tumor volume reduction}

There is clear evidence that SRL treatment induces tumor volume reduction in the majority of patients [53]. However, definitions of significant tumor reduction and optimal measurement are still under debate. Unsurprisingly, higher doses of SRLs were found to be more efficacious. Colao et al. in 2007 demonstrated that mean pituitary tumor volume was decreased by $68 \%$ after 24 months in patients treated with octreotide LAR at doses of up to $40 \mathrm{mg} / \mathrm{month}$ [51]. Furthermore, higher tumor volume reduction was detected at 24 months in patients who had their octreotide LAR dose increased to $40 \mathrm{mg} / \mathrm{month}$ (Fig. 5) [51]. These results led to a hypothesis and possible advantage of using initial high doses of octreotide LAR for macroadenomas [40]. In a 5-year study of patients with acromegaly, tumor shrinkage was 75 and $78 \%$ in the octreotide LAR (30$40 \mathrm{mg}$, every 28 days) and lanreotide ATG (60-120 mg, every 21-28 days) groups, respectively [54]. A systematic review of 22 studies published in 2010 found that $33 \%$ of patients experienced a variable degree of tumor volume reduction (from 10 to $77 \%$ ) during lanreotide SR or ATG treatment [55]. As expected, tumor reduction was more frequently observed in patients that were naïve to SRLs and had macroadenomas. No obvious correlation between biochemical response and tumor volume reduction has been noted in patients treated with lanreotide ATG. The observation that dose optimization can increase the number of patients achieving biochemical control [19] has been

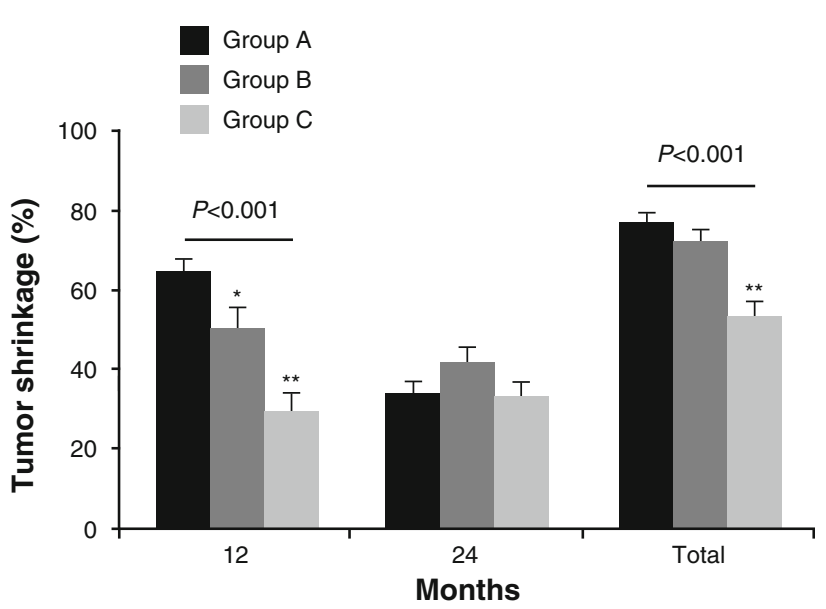

Fig. 5 Percent tumor volume reduction from baseline to 12 months of treatment (12), from 12 to 24 months of treatment (24) and total tumor shrinkage (from baseline to 24 months of treatment) in patients with acromegaly. Group A represents patients that were started and remained on the $20 \mathrm{mg} / \mathrm{month}$ dose. Group $B$ represents patients whose starting dose was increased to $30 \mathrm{mg} / \mathrm{month}$. Group $C$ represents patients whose dose was increased further to $40 \mathrm{mg} /$ month. (C) 2007, The European Society of Endocrinology, reproduced with permission. Colao et al. [51]. $* P<0.01$ versus same time Group A; $* * P<0.01$ versus same time Group A and B 
confirmed in another recent study. A randomized, 50-week trial designed to determine the benefit of first-line octreotide LAR treatment versus surgery demonstrated that $42 / 51$ (82\%) patients initially randomized to octreotide LAR $20 \mathrm{mg}$ required a dose increase to $30 \mathrm{mg}$ during the study in order to achieve biochemical control. In addition to biochemical control, at week 24 , the mean tumor volume for the octreotide LAR-treated group decreased by $21 \%$ from baseline, and by $35 \%$ by week 48 . Seventy-three percent of octreotide LAR-treated patients had significant ( $>20 \%$ ) tumor shrinkage over the 48 -week study period.

\section{Efficacy of "high-dose/high-frequency" SRLs}

More recently, in patients inadequately controlled on conventional doses of octreotide LAR (20-30 mg/month), both higher dose (>40 mg/month) or higher frequency administration (30 mg every 3 weeks) has been tested to determine if disease control can be improved [56]. In a prospective, open-label multicenter study, 28 patients who were responsive to conventional-dose SRL therapy but did not achieve biochemical control were treated with either high-dose $(60 \mathrm{mg} / \mathrm{month})$ or high-frequency octreotide LAR. After 24 weeks of treatment, 27\% (3/11) of patients treated with high-dose octreotide LAR achieved control of GH $(<2 \mu \mathrm{g} / \mathrm{l})$ and $36 \%(4 / 11)$ achieved normalization of IGF-1 [56]. More importantly, in the high-dose group, $90 \%$ of patients had noticeable decreases in IGF-1 levels (Fig. 6) [56].

Experience with high-dose ( $>120 \mathrm{mg} / \mathrm{month})$ or highfrequency (every 3 weeks) lanreotide ATG treatment is limited to case reports. In two patients with acromegaly who were not suitable for surgery, Wuster et al. increased the dose of lanreotide ATG sequentially up to $180 \mathrm{mg}$ every 3-4 weeks for 3-6 months if the biochemical response of the patient was unsatisfactory [57]. Tumor volume reduction was observed with no drug-related adverse events. Clinical use of high-dose lanreotide ATG therapy was reported for an additional six patients who were titrated up to $180 \mathrm{mg} / \mathrm{month}$ in two separate clinical studies [58, 59].

\section{Safety and tolerability of SRLs is maintained at higher doses}

SRLs are well tolerated in most patients and treatment discontinuations due to adverse events are generally related to transient gastrointestinal (GI) disturbances [43]. The most commonly reported adverse events are injection-site discomfort and erythema, GI disturbances (such as diarrhea, abdominal pain, nausea and vomiting), biliary sludge or gallstones, and abnormal glucose metabolism [60]. However, most adverse events are transient and of mild-tomoderate intensity. SRL treatment can create conditions that favor precipitation of microcrystals and stone formation; however, gallbladder sludge and gallstones are usually asymptomatic and do not require surgery [61], which was confirmed using ultrasound surveillance of patients with acromegaly treated with octreotide LAR [36]. Glucose metabolism in patients with acromegaly treated with SRLs is very complex. Excess of GH in acromegaly is frequently associated with insulin resistance [4]. SRLs significantly
Fig. 6 Patient IGF-1 levels at baseline $(T 0)$ and week $24(T 2)$ in patients receiving either highfrequency octreotide therapy (HF; $30 \mathrm{mg}$ every 21 days) or high-dose octreotide (HD; $60 \mathrm{mg}$ every 28 days) therapy. Shaded area indicates normal IGF-1 concentration range for age. (C) 2009, The European Society of Endocrinology, reproduced with permission. Giustina et al. [56]

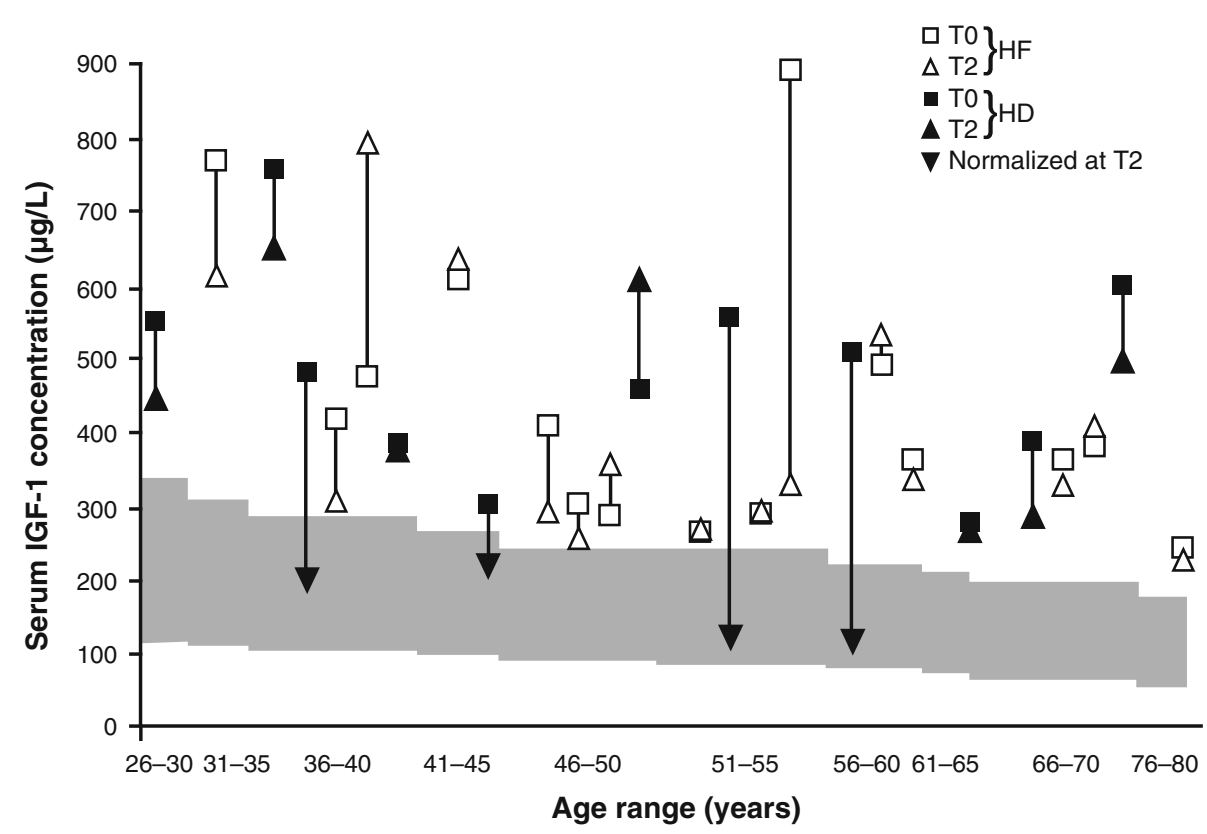

怘

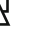

Age range (years) 
improve GH thus increasing insulin sensitivity, but experimental and clinical evidence suggests that this treatment could have negative effects on $\beta$-cell function [62]. Hypoglycemia has also been reported. A recent metaanalysis of 31 studies in patients treated with SRLs showed a statistically significant decrease in fasting plasma insulin, but without any significant change in fasting plasma glucose [63]. Clinical results from studies of patients with acromegaly treated with doses of octreotide LAR up to $60 \mathrm{mg} / \mathrm{month}$ show a similar safety profile to that reported with conventional treatment $(20-30 \mathrm{mg} /$ month $)$ with octreotide LAR. The adverse events reported from patients in the dose-optimization studies discussed above were very similar to conventional therapy with octreotide LAR and report mild adverse events mostly involving the gastrointestinal tract [32, 36, 51, 64]. Some studies reported nonsignificant increases in gallstones or gallbladder sludge [32, 51, 56]. A Japanese study evaluating octreotide LAR $40 \mathrm{mg} / \mathrm{month}$ for a duration of 40 months in patients with acromegaly reported that treatment was safe and did not effect glycosylated hemoglobin $\left(\mathrm{HbA}_{1 \mathrm{c}}\right)$ levels negatively [64]. Giustina et al. 2009 demonstrated no dose-response effect in terms of adverse events. A slight decrease in median $\mathrm{HbA}_{1 \mathrm{c}}$ was observed in the high-dose group (60 mg/month) but not in the high-frequency group (30 $\mathrm{mg}$ every 3 weeks) [56]. Studies of patients treated with doses of lanreotide ATG up to $120 \mathrm{mg}$ also report mainly GI adverse events. The case reports of patients treated with lanreotide ATG doses $\geq 120 \mathrm{mg}$ every 4 weeks revealed no unexpected adverse events [57].

\section{Conclusions}

Treatment approach should be individualized to take into consideration a patient's tumor size and location, symptoms, comorbid conditions, and preferences. Novel medical treatments with different therapeutic regimens using SRLs are gaining importance while a second wave of more effective drugs is in development. Careful monitoring of the medical therapy of acromegaly, both primary and adjuvant, plays an important role in successfully controlling the signs and symptoms of the disease. The current review of published clinical studies demonstrates that dose escalation could provide additional biochemical control of acromegaly in patients who are inadequately controlled with conventional starting doses of octreotide LAR (20 mg/month) and lanreotide ATG (90 mg every 4 weeks). Therefore, patients should routinely have their GH and IGF-1 levels monitored and their SRL dose increased or decreased thereafter according to their individual response. Furthermore, multiple studies have now proven that higher doses of octreotide LAR could provide additional efficacy without significantly changing the safety and adverse events seen with conventional doses. The potential long-term use of SRLs at doses higher than the maximum labeled dose should still be evaluated in prospective, randomized trials with respect to GH control, tumor shrinkage and safety profile. It is important to also consider the cost:benefit ratio of high-dose compared with combination therapy and the overall burden of uncontrolled disease and complications.

Acknowledgments The author would like to thank Shirley McCartney, Ph.D. and Tim Remus, Ph.D., for medical editorial assistance with this manuscript. Partial financial support (Tim Remus) for editorial assistance was provided by Novartis Pharmaceuticals Corporation.

Disclosures Dr. Fleseriu has received consultant fees from Novartis Pharmaceuticals, Tercica, Inc., and Endo Pharmaceuticals, and is a principal investigator in clinical trials sponsored by Novartis Pharmaceuticals and Ipsen Pharma and co-investigator in a clinical trial sponsored by Endo Pharmaceuticals.

Open Access This article is distributed under the terms of the Creative Commons Attribution Noncommercial License which permits any noncommercial use, distribution, and reproduction in any medium, provided the original author(s) and source are credited.

\section{References}

1. Etxabe J, Gaztambide S, Latorre P, Vazquez JA (1993) Acromegaly: an epidemiological study. J Endocrinol Invest 16:181-187

2. Holdaway IM, Rajasoorya C (1999) Epidemiology of acromegaly. Pituitary 2:29-41

3. Daly AF, Rixhon M, Adam C, Dempegioti A, Tichomirowa MA, Beckers A (2006) High prevalence of pituitary adenomas: a cross-sectional study in the province of Liege, Belgium. J Clin Endocrinol Metab 91:4769-4775

4. Melmed S (2006) Medical progress: acromegaly. N Engl J Med 355:2558-2573

5. Dekkers OM, Biermasz NR, Pereira AM, Romijn JA, Vandenbroucke JP (2008) Mortality in acromegaly: a metaanalysis. J Clin Endocrinol Metab 93:61-67

6. Holdaway IM, Rajasoorya RC, Gamble GD (2004) Factors influencing mortality in acromegaly. J Clin Endocrinol Metab 89:667-674

7. Biermasz NR, Van Thiel SW, Pereira AM, Hoftijzer HC, van Hemert AM, Smit JW, Romijn JA, Roelfsema F (2004) Decreased quality of life in patients with acromegaly despite long-term cure of growth hormone excess. J Clin Endocrinol Metab 89:5369-5376

8. Holdaway IM, Bolland MJ, Gamble GD (2008) A meta-analysis of the effect of lowering serum levels of GH and IGF-I on mortality in acromegaly. Eur J Endocrinol 159:89-95

9. AACE Acromegaly Guidelines Task Force (2004) AACE medical guidelines for clinical practice for the diagnosis and treatment of acromegaly. Endocr Pract 10:213-225

10. Melmed S, Colao A, Barkan A, Molitch M, Grossman AB, Kleinberg D, Clemmons D, Chanson P, Laws E, Schlechte J, Vance ML, Ho K, Giustina A (2009) Guidelines for acromegaly management: an update. J Clin Endocrinol Metab 94:1509-1517 
11. Giustina A, Barkan A, Casanueva FF, Cavagnini F, Frohman L, Ho K, Veldhuis J, Wass J, von Werder K, Melmed S (2000) Criteria for cure of acromegaly: a consensus statement. J Clin Endocrinol Metab 85:526-529

12. Giustina A, Chanson P, Bronstein MD, Klibanski A, Lamberts S, Casanueva FF, Trainer P, Ghigo E, Ho K, Melmed S (2010) A consensus on criteria for cure of acromegaly. J Clin Endocrinol Metab 95:3141-3148

13. Beauregard C, Truong U, Hardy J, Serri O (2003) Long-term outcome and mortality after transsphenoidal adenomectomy for acromegaly. Clin Endocrinol (Oxf) 58:86-91

14. De P, Rees DA, Davies N, John R, Neal J, Mills RG, Vafidis J, Davies JS, Scanlon MF (2003) Transsphenoidal surgery for acromegaly in wales: results based on stringent criteria of remission. J Clin Endocrinol Metab 88:3567-3572

15. Nomikos P, Buchfelder M, Fahlbusch R (2005) The outcome of surgery in 668 patients with acromegaly using current criteria of biochemical 'cure'. Eur J Endocrinol 152:379-387

16. Shimon I, Cohen ZR, Ram Z, Hadani M (2001) Transsphenoidal surgery for acromegaly: endocrinological follow-up of 98 patients. Neurosurgery 48:1239-1243

17. Fleseriu M, Delashaw JB, Cook DM (2010) Acromegaly: a review of current medical therapy and new drugs on the horizon. Neurosurg Focus 29:E15

18. Anthony L, Freda PU (2009) From somatostatin to octreotide LAR: evolution of a somatostatin analogue. Curr Med Res Opin 25:2989-2999

19. Colao A, Cappabianca P, Caron P, De Menism E, Farrall AJ, Gadelha MR, Hmissi A, Rees A, Reincke M, Safari M, T'Sjoen G, Bouterfa H, Cuneo RC (2009) Octreotide LAR vs. surgery in newly diagnosed patients with acromegaly: a randomized, openlabel, multicentre study. Clin Endocrinol (Oxf) 70:757-768

20. Murray RD, Kim K, Ren S-G, Chelly M, Umehara Y, Melmed S (2004) Central and peripheral actions of somatostatin on the growth hormone-IGF-I axis. J Clin Invest 114:349-356

21. Schmid HA (2008) Pasireotide (SOM230): development, mechanism of action and potential applications. Mol Cell Endocrinol 286:69-74

22. Casarini AP, Jallad RS, Pinto EM, Soares IC, Nonogaki S, Giannella-Neto D, Musolino NR, Alves VA, Bronstein MD (2009) Acromegaly: correlation between expression of somatostatin receptor subtypes and response to octreotide-lar treatment. Pituitary 12:297-303

23. Petersenn S, Schopohl J, Barkan A, Mohideen P, Colao A, Abs R, Buchelt A, Ho Y-Y, Hu K, Farrall AJ, Melmed S, Biller BM (2010) Pasireotide (SOM230) demonstrates efficacy and safety in patients with acromegaly: a randomized, multicenter, Phase II trial. J Clin Endocrinol Metab 95:2781-2789

24. Wilson C (2010) Pharmacotherapy: Pasireotide shows promise for the treatment of acromegaly. Nat Rev Endocrinol 6:417

25. Colao A, Faggiano A, Pivonello R (2010) Somatostatin analogues: treatment of pituitary and neuroendocrine tumors. Prog Brain Res 182:281-294

26. Flogstad AK, Halse J, Bakke S, Lancranjan I, Marbach P, Bruns C, Jervell J (1997) Sandostatin LAR in acromegalic patients: long-term treatment. J Clin Endocrinol Metab 82:23-28

27. Stewart PM, Kane KF, Stewart SE, Lancranjan I, Sheppard MC (1995) Depot long-acting somatostatin analog (Sandostatin-LAR) is an effective treatment for acromegaly. J Clin Endocrinol Metab 80:3267-3272

28. Caron P, Beckers A, Cullen DR, Goth MI, Gutt B, Laurberg P, Pico AM, Valimaki M, Zgliczynski W (2002) Efficacy of the new long-acting formulation of lanreotide (lanreotide Autogel) in the management of acromegaly. J Clin Endocrinol Metab 87:99-104

29. Caron P, Bex M, Cullen DR, Feldt-Rasmussen U, Pico Alfonso AM, Pynka S, Racz K, Schopohl J, Tabarin A, Valimaki MJ
(2004) One-year follow-up of patients with acromegaly treated with fixed or titrated doses of lanreotide Autogel. Clin Endocrinol (Oxf) 60:734-740

30. Ronchi CL, Boschetti M, Uberti EC, Mariotti S, Grottoli S, Loli P, Lombardi G, Tamburrano G, Arvigo M, Angeletti G, Boscani PF, Beck-Peccoz P, Arosio M (2007) Efficacy of a slow-release formulation of lanreotide (Autogel $120 \mathrm{mg}$ ) in patients with acromegaly previously treated with octreotide long acting release (LAR): an open, multicentre longitudinal study. Clin Endocrinol (Oxf) 67:512-519

31. Bevan JS, Atkin SL, Atkinson AB, Bouloux P-M, Hanna F, Harris PE, James RA, McConnell M, Roberts GA, Scanlon MF, Stewart PM, Teasdale E, Turner HE, Wass JA, Wardlaw JM (2002) Primary medical therapy for acromegaly: an open, prospective, multicenter study of the effects of subcutaneous and intramuscular slow-release octreotide on growth hormone, insulin-like growth factor-I, and tumor size. J Clin Endocrinol Metab 87:4554-4563

32. Colao A, Ferone D, Marzullo P, Cappabianca P, Cirillo S, Boerlin V, Lancranjan I, Lombardi G (2001) Long-term effects of depot long-acting somatostatin analog octreotide on hormone levels and tumor mass in acromegaly. J Clin Endocrinol Metab 86:2779-2786

33. Colao A, Pivonello R, Rosato F, Tita P, De Menis E, Barreca A, Ferrara R, Mainini F, Arosio M, Lombardi G (2006) First-line octreotide-LAR therapy induces tumor shrinkage and controls hormone excess in patients with acromegaly: results from an open, prospective, multicentre trial. Clin Endocrinol (Oxf) 64:342-351

34. Cozzi R, Attanasio R, Montini M, Pagani G, Lasio G, Lodrini S, Barausse M, Albizzi M, Dallabonzana D, Pedroncelli AM (2003) Four-year treatment with octreotide-long-acting repeatable in 110 acromegalic patients: predictive value of short-term results? J Clin Endocrinol Metab 88:3090-3098

35. Cozzi R, Montini M, Attanasio R, Albizzi M, Lasio G, Lodrini S, Doneda P, Cortesi L, Pagani G (2006) Primary treatment of acromegaly with octreotide LAR: a long-term (up to 9 years) prospective study of its efficacy in the control of disease activity and tumor shrinkage. J Clin Endocrinol Metab 91:1397-1403

36. Lancranjan I, Atkinson AB (1999) Results of a European multicentre study with Sandostatin ${ }^{\circledR}$ LAR $^{\circledR}$ in acromegalic patients. Sandostatin LAR group. Pituitary 1:105-114

37. Mercado M, Borges F, Bouterfa H, Chang T-C, Chervin A, Farrall AJ, Patocs A, Petersenn S, Podoba J, Safari M, Wardlaw J (2007) A prospective, multicentre study to investigate the efficacy, safety and tolerability of octreotide LAR $^{\circledR}$ (long-acting repeatable octreotide) in the primary therapy of patients with acromegaly. Clin Endocrinol (Oxf) 66:859-868

38. Caron P, Morange-Ramos I, Cogne M, Jaquet P (1997) Three year follow-up of acromegalic patients treated with intramuscular slow-release lanreotide. J Clin Endocrinol Metab 82:18-22

39. Giusti M, Ciccarelli E, Dallabonzana D, Delitala G, Faglia G, Liuzzi A, Gussoni G, Giordano DG (1997) Clinical results of long-term slow-release lanreotide treatment of acromegaly. Eur J Clin Invest 27:277-284

40. Colao A, Lombardi G (2010) Dose optimization of somatostatin analogues for acromegaly patients. $\mathrm{J}$ Endocrinol Invest 33:125-127

41. James RA, Gilroy J (2001) Dose and frequency titration of somatostatin analogues in the treatment of acromegaly - an injection of expediency? Clin Endocrinol (Oxf) 54:11-13

42. Jenkins PJ, Akker S, Chew SL, Besser GM, Monson JP, Grossman AB (2000) Optimal dosage interval for depot somatostatin analogue therapy in acromegaly requires individual titration. Clin Endocrinol (Oxf) 53:719-724 
43. Melmed S, Casanueva F, Cavagnini F, Chanson P, Frohman LA, Gaillard R, Ghigo E, Ho K, Jaquet P, Kleinberg D, Lamberts S, Laws E, Lombardi G, Sheppard MC, Thorner M, Vance ML, Wass JA, Giustina A (2005) Consensus statement: medical management of acromegaly. Eur J Endocrinol 153:737-740

44. Feelders RA, Hofland LJ, van Aken MO, Neggers SJ, Lamberts SW, de Herder WW, van der Lely A-J (2009) Medical therapy of acromegaly: efficacy and safety of somatostatin analogues. Drugs 69:2207-2226

45. Murray RD, Melmed S (2008) A critical analysis of clinically available somatostatin analog formulations for therapy of acromegaly. J Clin Endocrinol Metab 93:2957-2968

46. Freda PU, Katznelson L, van der Lely AJ, Reyes CM, Zhao S, Rabinowitz D (2005) Long-acting somatostatin analog therapy of acromegaly: a meta-analysis. J Clin Endocrinol Metab 90:4465-4473

47. Ayuk J, Sheppard MC (2006) Growth hormone and its disorders. Postgrad Med J 82:24-30

48. Ayuk J, Sheppard MC (2008) Does acromegaly enhance mortality? Rev Endocr Metab Disord 9:33-39

49. Chanson P, Borson-Chazot F, Kuhn J-M, Blumberg J, Maisonobe P, Delemer B (2008) Control of IGF-I levels with titrated dosing of lanreotide Autogel over 48 weeks in patients with acromegaly. Clin Endocrinol (Oxf) 69:299-305

50. Melmed S, Cook D, Schopohl J, Goth MI, Lam KS, Marek J (2010) Rapid and sustained reduction of serum growth hormone and insulin-like growth factor- 1 in patients with acromegaly receiving lanreotide Autogel $((\mathrm{R}))$ therapy: a randomized, placebo-controlled, multicenter study with a 52 week open extension. Pituitary 13:18-28

51. Colao A, Pivonello R, Auriemma RS, Galdiero M, Savastano S, Lombardi G (2007) Beneficial effect of dose escalation of Octreotide-LAR as first-line therapy in patients with acromegaly. Eur J Endocrinol 157:579-587

52. Colao A, Auriemma RS, Rebora A, Galdiero M, Resmini E, Minuto F, Lombardi G, Pivonello R, Ferone D (2009) Significant tumour shrinkage after 12 months of Lanreotide Autogel-120 mg treatment given first-line in acromegaly. Clin Endocrinol (Oxf) 71:237-245

53. Amato G, Mazziotti G, Rotondi M, Iorio S, Doga M, Sorvillo F, Manganella G, Di Salle F, Giustina A, Carella C (2002) Longterm effects of lanreotide SR and octreotide $\mathrm{LAR}^{\circledR}$ on tumour shrinkage and GH hypersecretion in patients with previously untreated acromegaly. Clin Endocrinol (Oxf) 56:65-71

54. Colao A, Auriemma RS, Galdiero M, Lombardi G, Pivonello R (2009) Effects of initial therapy for five years with somatostatin analogs for acromegaly on growth hormone and insulin-like growth factor-I levels, tumor shrinkage, and cardiovascular disease: a prospective study. J Clin Endocrinol Metab 94:3746-3756
55. Mazziotti G, Giustina A (2010) Effects of lanreotide SR and Autogel on tumor mass in patients with acromegaly: a systematic review. Pituitary 13:60-67

56. Giustina A, Bonadonna S, Bugari G, Colao A, Cozzi R, Cannavo S, De Marinis L, Degli Uberti E, Bogazzi F, Mazziotti G, Minuto F, Montini M, Ghigo E (2009) High-dose intramuscular octreotide in patients with acromegaly inadequately controlled on conventional somatostatin analogue therapy: a randomised controlled trial. Eur J Endocrinol 161:331-338

57. Wuster C, Both S, Cordes U, Omran W, Reisch R (2010) Primary treatment of acromegaly with high-dose lanreotide: a case series. J Med Case Reports 4:85

58. Attanasio R, Lanzi R, Losa M, Valentini F, Grimaldi F, De ME, Davi MV, Battista C, Castello R, Cremonini N, Razzore P, Rosato F, Montini M, Cozzi R (2008) Effects of lanreotide Autogel on growth hormone, insulinlike growth factor 1, and tumor size in acromegaly: a 1-year prospective multicenter study. Endocr Pract 14:846-855

59. Toledano Y, Rot L, Greenman Y, Orlovsky S, Pauker Y, Olchovsky D, Eliash A, Bardicef O, Makhoul O, Tsvetov G, Gershinsky M, Cohen-Ouaqnine O, Ness-Abramof R, Adnan Z, Ilany J, Guttmann H, Sapir M, Benbassat C, Shimon I (2009) Efficacy of long-term lanreotide treatment in patients with acromegaly. Pituitary 12:285-293

60. Freda PU (2002) Somatostatin analogs in acromegaly. J Clin Endocrinol Metab 87:3013-3018

61. Cozzi R, Attanasio R (2007) Octreotide for acromegaly. Expert Rev Endocrinol Metab 2:129-145

62. Baldelli R, Battista C, Leonetti F, Ghiggi M-R, Ribaudo M-C, Paoloni A, D'Amico E, Ferretti E, Baratta R, Liuzzi A, Trischitta V, Tamburrano G (2003) Glucose homeostasis in acromegaly: effects of long-acting somatostatin analogues treatment. Clin Endocrinol (Oxf) 59:492-499

63. Mazziotti G, Floriani I, Bonadonna S, Torri V, Chanson P, Giustina A (2009) Effects of somatostatin analogs on glucose homeostasis: a metaanalysis of acromegaly studies. J Clin Endocrinol Metab 94:1500-1508

64. Yetkin DO, Boysan SN, Tiryakioglu O, Yalin AS, Kadioglu P (2007) Forty-month follow-up of persistent and difficultly controlled acromegalic patients treated with depot long acting somatostatin analog octreotide. Endocr J 54:459-464

65. Melmed S, Cook D, Schopohl J, Goth MI, Lam KS, Marek J (2010) Rapid and sustained reduction of serum growth hormone and insulin-like growth factor-1 in patients with acromegaly receiving lanreotide Autogel((R)) therapy: a randomized, placebo-controlled, multicenter study with a 52 week open extension. Pituitary 13:18-28 